\title{
Peribulbar Block Using Dexmedetomdine versus Magnesium Sulphate as Additives to Local Anesthetics for Cataract Surgery \\ Manal Foad Abd Elmoniem ${ }^{1}$ and Rehab Moustafa Kamel ${ }^{2 *}$
}

1 Anesthiology, Intensive Care and Pain Management Department, 2 Ophthalmology Department, Faculty of Medicine for Girls, Al-Azhar University

*Corresponding Author: Rehab Moustafa Kamel, Phone No.: (+2) 01026332337, E-mail: rehabmoustafakamel@yahoo.com

\begin{abstract}
Background: peribulbar block is commonly used for cataract surgery in adults, most commonly local anesthetics were injected into peribulbar space, but using only local anesthetics for peribulbar anesthesia is associated with delayed onset of globe akinesia and, short duration of analgesia and frequent need of block supplementation

Objective: to assess the efficacy and safety of addition of dexmedetomidine versus magnesium sulphate to local anesthetic mixture for peribulbar block in cataract surgery.

Patients and Methods: the patients were divided randomly into two equal groups: Dexmedetomidine group (D Group) included 30 patients who received $50 \mu \mathrm{g}$ dexmedetomidine adjuvant to local anesthetics mixture (lidocaine and bupivacaine). Magnesium sulphate group (M Group) included 30 patients who received 50mg of Magnesium sulphate adjuvant to local anesthetics mixture (lidocaine and bupivacaine).

Results: The addition of Dexmedetomidine or Magnesium sulphate to local anesthetic in cataract surgery accelerates the onset of corneal anesthesia and globe akinesia. The decrease in the IOP is more in D Group . No significant changes in the hemodynamic measurements in both groups

Conclusion: Use of 50ug dexmedatomedine or 50mg magnesium sulphate $10 \%$ with mixture of lidocaine $2 \%$ plus bupivacine $0.5 \%$ for peribulbar anesthesia in cataract surgery enhances the onset of globe anesthesia and akinesia . Dexmedetomidine causes more decrease in intraocular pressure magnesium sulphate .
\end{abstract}

Keywords: Dexmedetomidine - Magnesium sulphate - Peri bulbar block.

\section{INTRODUCTION}

local anesthesia is the best method for eye surgeries especially is old patients with systemic disease who are more liable for complications of anesthesia. Retro bulbar technique provides adequate anesthesia, decrease in intraocular pressure, akinesia and post operative analgesia . (1) But it has many complications as globe perforation, retro bulbar hemorrhage and brain stem anesthesia (2). Peribulbar block with local anesthetics is commonly used for cataract surgery in adults but using only local anesthetics for peribulbar anesthesia is associated with delayed onset of globe akinesia and, short duration of analgesia and frequent need of block supplementation. To decrease the time of onset of action and increase the duration of analgesia, many additives such as hyalouronidase, sodium bicarbonate, adrenaline, corticosteroids and opioids were added to local anesthetics with limited success $(\mathbf{3 , 4 , 5 )}$. Until now no adjuvant is considered superior than others in prevention of local anesthetic complications like dryness of mouth, bradycardica, and allergic reaction ('). Magnesium sulphate (MgSo4) is a non-competitive Nmethyl-D-Aspartate [NAMDA] antagonist and calcium channel blocker ${ }^{(7)}$ , it has been used as additive to LA solution to hasten the onset time of block and prolong the duration of the anesthesia ${ }^{(8)}$. Dexmedetomdine is a selective agonist that have an eight fold greater affinity for $\alpha 2$ adrenergic receptors ( hypnotic and analgesic effect) than clonidine. It accelerates central and peripheral neural blockade when added to LA ${ }^{(9,10)}$. The aim of this study is to compare the safety and efficacy of the addition of dexmedetomedine or magnesium to mixture of local anesthetics in cataract surgery by measuring onset of globe akinesia, corneal anesthesia and adequate time for surgery, Intraocular pressure and hemodynamic parameters ( primary outcome) ,first request of analgesia and patient and doctor satisfaction (secondary outcome ) .

\section{PATIENTS AND METHODS}

A prospective randomized, comparative non controlled clinical study was carried out at AlZahraa university hospital between June 2017 to Auguat 2018 . The study protocol adhered to the tenets of declaration of Helsinki and was approved by the ethics board of Al Azhar university. An informed written consent was taken from each participant in the study .

The study included 60 patients physical stated ASA I or II of either sexes aged between 20 to 60 years scheduled for elective cataract surgery under peribulbar anesthesia.

In this study we excluded morbid obese patient with body mass index $>35$, patients with uncontrolled hypertensions or diabetes, deafness, or with disturbed level of consciousness. Patients with axial eye length globe more than $25 \mathrm{~mm}$ or with posterior staphyloma, patients on anticoagulant drugs were also excluded.

The patients were randomly allocated to one of two groups: 
D group (Dexmedetomdine group) $n=30$ : Each patient received $7 \mathrm{ml}$ combination of $3 \mathrm{ml}$ of lidocaine $2 \%, 3 \mathrm{ml}$ of bupivacaine $0.5 \%$ and $50 \mathrm{ug}$ of dexmedetomdine in $1 \mathrm{ml}$ saline $0.9 \%$.

M group (Magnesium group) $\mathrm{n}=30$ : Each patient received $7 \mathrm{ml}$ combination of $3 \mathrm{ml}$ of lidocaine $2 \%$, $3 \mathrm{ml}$ of bupivacaine $0.5 \%$ and $50 \mathrm{mg}$ of Magnesium sulphate in $1 \mathrm{ml}$ of saline $0.9 \%$.

At the operating room, 22 or 20 gauge cannula was inserted in the dorsum of the non dominant hand and the patient were connected to (Nitton KoHden Corporation) monitor to record the heart rate(HR) and mean arterial blood pressure (MAP) and $\mathrm{O} 2$ saturation. Anesthetic machine and resuscitative equipment's and drugs were checked. patients lies in natural position

Anesthetic technique : after sterilization of doctor hands and patient eye the topical anesthetic drops (Benoxinata HCL 0.4\%) was conducted to patients eye.The injection was carried by using 26 guge, 13 $\mathrm{mm}$. Short bevel needle connected to syringe contained with adjuvant according to patients group. The needle was introduced at two points, $3.5 \mathrm{ml}$ of local anesthetic with adjuvant were injected in each point, after negative aspiration, The first injection is given inferiorly at the junction of outer one third and inner two third of the lower orbital rim( up to $5 \mathrm{cc}$ ). The second injection is given superonasally beneath the superior orbital notch (3- $4 \mathrm{cc})$. Immediately following this injection gentle intermittent pressure is applied on the eye for 10-15 minutes.

\section{Drugs used in the study:}

- Benox.(epico Egypt) as topical anesthesia.

- Lidocaine $2 \%$ vail (Alex pharmaceutical)

- Bupivacaine $0.5 \%$ vial (sunny pharmaceutical Egypt).

- Magnesium sulphate $100 \mathrm{mg} / \mathrm{mL}$ ampule (Epicopharma Egypt)

- Dexmedetomidine 200ug/ 2ml (Hospira, USA)

\section{Parameters of assessment}

1. Corneal anesthesia was evaluated using cotton wick every $30 \mathrm{sec}$. till the onset of anesthesia.

2. Ocular movement was evaluated every $2.5 \mathrm{~min}$. interval in all four directions using 3 points scale, 0 =complete akinesia, $1=$ limited akinesia, $2=$ normal movements. If a block is inadequate for more than 10 min additional injection of $3 \mathrm{ml}$ of local anesthetic solution was given at medial canthus.

3. Intraocular pressure IOP was measured $5 \mathrm{~min}$ before \& $5 \mathrm{~min}$ after LA injection by Perkin's applanation tonometer .

4. Hemodynamic parameters; mean arterial blood pressure (MAP)\& heart rate (HR ) were recorded every $5 \mathrm{~min}$.

5.Adequate time for operations defined as the presence of corneal anesthesia together with an ocular movement $\leq 1$ in all directions and eye lid akinesia score 0

6.Injection of supplementary of LA $10 \mathrm{~min}$ doses after injection.

7. Surgeon's and patients' satisfaction using verbal rating scale; from $0=$ total dis-satisfaction to $10=$ total satisfaction.

8. First request of analgesia.

9. Complications during and after block as nausea, vomiting, convulsion, allergy and failed block.

Statistical design : All data were analyzed using SAS_ (release 6.12 for Windows). The collected data were revised, coded, tabulated using statistical package for social science (SPSS 15.01 for windows; SPSS Inc, Chicago, IL, 2001).

\section{RESULTS}

Demographic characteristics : included age, sex, ASA classification and duration of surgery are reported in table (1). There's was no statistically significant difference between the two studied groups.

Table (1): demographic characteristics as (mean \pm SD) for the studied groups

\begin{tabular}{|c|c|c|c|c|c|}
\hline Variables & \multicolumn{2}{|c|}{$\begin{array}{l}\text { group D } \\
(\mathrm{n}=30)\end{array}$} & \multicolumn{2}{|c|}{$\begin{array}{l}\text { group M } \\
(\mathrm{n}=30)\end{array}$} & $P$ value \\
\hline Age(y) & \multicolumn{2}{|c|}{$52.1 \pm 8.9$} & \multicolumn{2}{|c|}{$55.2 \pm 7.4$} & 0.148 \\
\hline Sex & $\mathrm{n}$ & $\%$ & $\mathrm{n}$ & $\%$ & \\
\hline Male & 20 & $(66.7)$ & 17 & $(56.7)$ & 0.426 \\
\hline Female & 10 & $(33.3)$ & 13 & $(43.3)$ & \\
\hline Weight $(\mathrm{kg})$ & \multicolumn{2}{|c|}{$91 \pm 11$} & \multicolumn{2}{|c|}{$87 \pm 16$} & 0.264 \\
\hline ASA classification & $\mathrm{n}$ & $\%$ & $\mathrm{n}$ & $\%$ & 0436 \\
\hline ASA I & 15 & (50) & 12 & (40) & 0.450 \\
\hline ASA II & 15 & $(50)$ & 18 & $(60)$ & \\
\hline Duration of surgery(min) & \multicolumn{2}{|c|}{$52 \pm 8$} & \multicolumn{2}{|c|}{$57 \pm 12$} & 0.063 \\
\hline
\end{tabular}

The onset of sensory block and globe akinesia were more rapid for group D but with no statistically significant difference . p-value were 0.324 for sensory block and 0.523 for globe akinesia (table 2). 
Table (2): onset of sensory block (min)

\begin{tabular}{|l|l|l|l|c|}
\hline & $\begin{array}{l}\text { group D } \\
(\mathrm{n}=30)\end{array}$ & $\begin{array}{l}\text { group M } \\
(\mathrm{n}=30)\end{array}$ & $\begin{array}{l}\text { Test } \\
\text { value }\end{array}$ & P-value \\
\hline $\begin{array}{l}\text { Onset time of } \\
\text { sensory block (min) }\end{array}$ & $2.05 \pm 0.65$ & $2.25 \pm 0.89$ & 0.994 & 0.324 \\
\hline $\begin{array}{l}\text { Onset time of globe } \\
\text { akinesia (min). }\end{array}$ & $2.9 \pm 1.1$ & $3.1 \pm 1.3$ & 0.643 & 0.523 \\
\hline
\end{tabular}

D Group had shorter adequate time for operation than M group without statistically significant difference between the two groups $\mathrm{P}$ value 0.267 (table 3 ).

Table (3): adequate time for operation.

\begin{tabular}{|l|l|l|l|l|}
\hline & group D $(\mathrm{n}=30)$ & group M $(\mathrm{n}=30)$ & Test value & P-value \\
\hline Adequate time for operation & $6.7 \pm 1.6$ & $7.24 \pm 2.1$ & 1.120 & 0.267 \\
\hline
\end{tabular}

The intraocular pressure 5 minutes after block were lower for D group than $\mathrm{M}$ group and the difference were statistically highly significant $\mathrm{p}$ value 0.001 (table 4).

Table (4): intraocular pressure (IOP)

\begin{tabular}{|l|l|l|l|l|}
\hline & Group D $(\mathrm{n}=30)$ & Group M $(\mathrm{n}=30)$ & Test value & P-value \\
\hline IOP 5 min before block & $14.7 \pm 1.2$ & $15.4 \pm 1.5$ & 1.996 & 0.051 \\
\hline IOP 5 min after block & $12.3 \pm 1.4$ & $14.6 \pm 1.6$ & 5.925 & 0.001 \\
\hline
\end{tabular}

Only 2(6.7\%) patients in group D received supplementary dose of anesthesia while the number of patients were 9 (30.0\%) in group $M$. this difference was statistically significant $\mathrm{p}$ value 0.019 (table 5).

Table (5): Supplementary doses of injection

\begin{tabular}{|l|l|l|l|l|}
\hline & Group D & Group M & Test value & P-value \\
\cline { 1 - 3 } No need & $28(93.3 \%)$ & $21(70.0 \%)$ & \multirow{2}{*}{5.455} & \multirow{2}{*}{0.019} \\
\hline Need & $2(6.7 \%)$ & 9 & & \\
\hline
\end{tabular}

There were statistically no significant difference between the 2 groups regarding the changes in the heart rate (Fig. 1) and Mean arterial blood pressure (Fig. 2) .

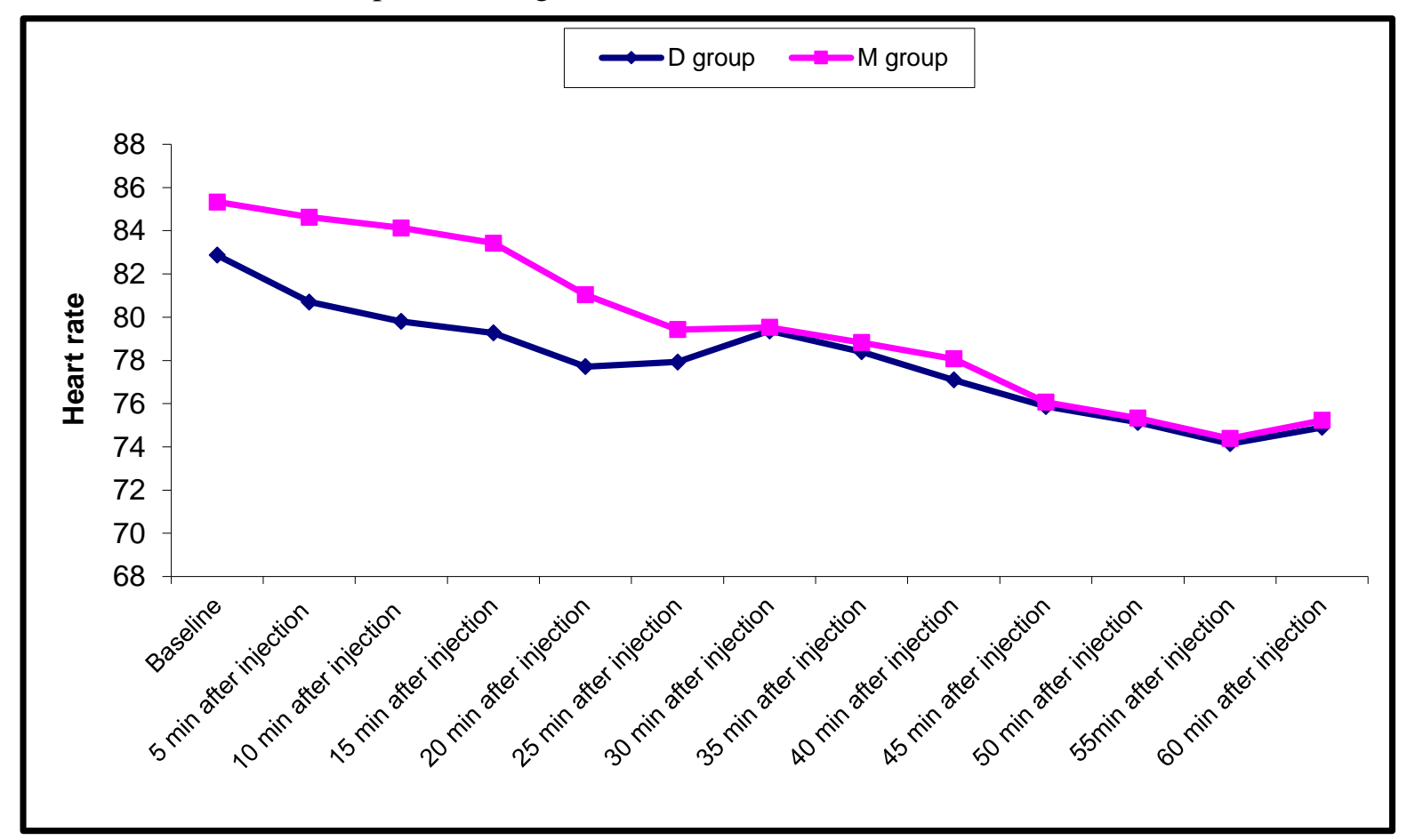

Fig. (1) HR changes in the two studied groups. 


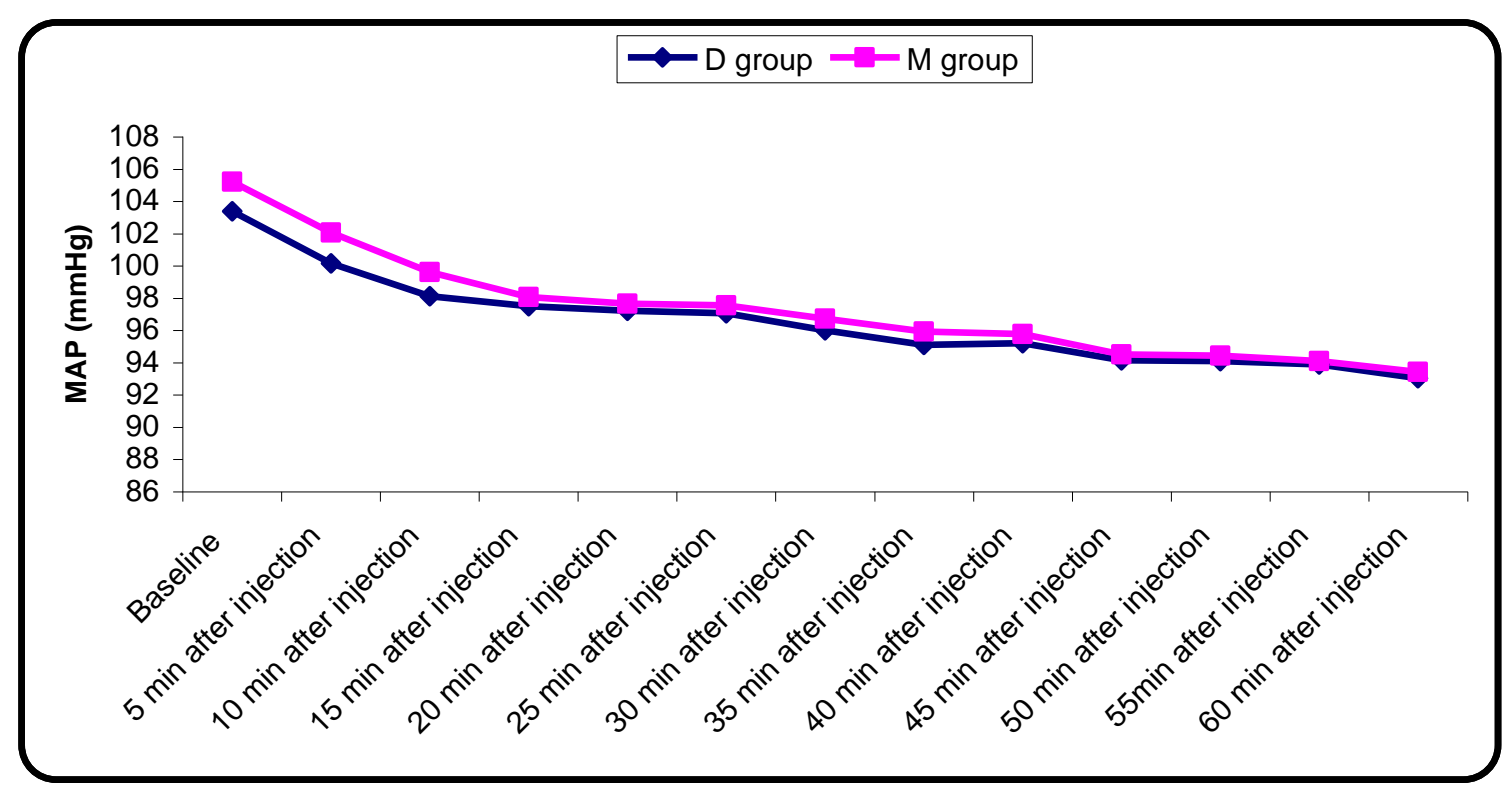

Fig. (2): MAP changes in the two studied groups.

As regard patients and surgeon's satisfaction there were no statistically significant difference between the two groups. P value was 0.577 for patient satisfaction and 0.111 for surgeons (table 6).

\begin{tabular}{|l|l|l|l|l|}
\hline & D group & M group & Test value & P-value \\
\hline Numbers of patients with complete satisfaction & $25(83.3 \%)$ & $27(90.0 \%)$ & 0.577 & 0.447 \\
\hline Numbers of surgeon's with perfect satisfaction & $25(83.3 \%)$ & $24(80.0 \%)$ & 0.111 & 0.739 \\
\hline
\end{tabular}

Table (6) patients and surgeon's satisfaction

The mean time for first analgesic request were $245 \pm 25.0$ min for $\mathrm{D}$ group and $239 \pm 31.5$ for $\mathrm{M}$ group with statistically no significant difference between the two groups.

As regard the complications during and after peribulbar anesthesia, there were no complications detected in the two groups.

\section{DISCUSSION}

Many authors studied the effect of addition different additives to local anesthetic mixture to improve the quality of ophthalmic block with different results ${ }^{(\mathbf{1 1})}$.

This study revealed that addition of 50 ug dexmedetomdine or 50mg magnesium sulphate to mixture of LA (lidocaine $2 \%$ plus bupivacaine $0.5 \%$ ) in peribulbar anesthesia for cataract surgery enhance the onset time of sensory block, globe akinesia , time for start surgery and increase the time for first request of analgesia with little effect on hemodynamic also increase the patients and doctors satisfaction and improve the quality of operative conditions without marked complications.

The results of this study go with other authors ${ }^{(12)}$ who found that the addition of different doses of dexmedetomedine $25 \mathrm{ug}$ or $50 \mathrm{ug}$ to local anesthetic mixture in cataract surgery enhances the onset of peribulbar anesthesia, prolongs the duration and increase time of postoperative analgesia, also found the addition of 50ug dexmedetomidine to local anesthetic mixture produces more sedation and patients satisfaction.
The results of present study supported with Hafez et al ${ }^{(13)}$, who examined the effect of addition different doses of dexmetetomdine (15 ug, $25 \mathrm{ug}$ and $50 \mathrm{ug}$ ) to local anesthetic mixture for peripbulbar anesthesia in vitreoretinal operations and found that dexmedetomedine accelerated the onset of sensory and motor block and increased the analgesic time. The results of this study is in line with the results of Abdelhamid (14) who found the addition of magnesium to LA mixture in peribulbar anesthesia accelerate the sensory and motor block in cataract surgery without any side hazards.

Also Osama et al. ${ }^{(15)}$ found that addition of $15 \mathrm{ug}$ dexmetetomidine or $50 \mathrm{mg}$ magnesium sulphate $10 \%$ to local anesthesia mixture of (Xylocaine $2 \%$ plus bupivacaine $0.5 \%$ ) in the cataract operations accelerated the corneal anesthesia, akinesia and prolonged the duration of anesthesia and analgesia and improve the quality of the operative condition.

On the other hand other authors (16) found that adding $50 \mathrm{mg}$ magnesium sulphate to mixture of lidocaine $2 \%$ and bupivacaine $0.5 \%$ had no effect on the onset of peribulbar block or akinesia score. 
Regarding intraocular pressure measurement. This study is in line with other authors ${ }^{(9,14)}$ who reported that addition of dexmedetomidine to local anesthesia mixture of xylocaine $2 \%$ and bupivacaine $0.5 \%$ led to significant decrease of intraocular pressure.

The results of this study coincide with that done by El Kabarity and Khashaba ${ }^{(17)}$ on patients scheduled for elective vitreoretinal surgery. They found adding dexmetetomidine to mixture of LA significantly accelerated the onset of sensory and motor block and prolonged duration of lid and globe akinesia.

As regard of hemodynamic (MAP and HR) Tripathi et al. ${ }^{(18)}$ found that adding of $\alpha 2$ agonist to bupivacine in supracalvicular brachial plexus block, give more hemodynamic stability. Also other authors $^{(14)}$ demonstrated that adding of dexmedetomidine to local anesthesia provide satisfactory level of hemodynamic stability with intraoperative sedation in peribulbar block. Regarding to side effect, this study is in line with Shivakumar et al (9) who found that the dexmedetomidine as adjuvant to local anesthetic mixture provides sedation without respiratory depression.The use of 50ug dexmedatomedine or $50 \mathrm{mg}$ magnesium sulphate $10 \%$ with mixture of lidocaine $2 \%$ plus bupivacine $0.5 \%$ for peribulbar anesthesia in cataract surgery enhances the onset of globe anesthesia and akinesia, Prolonge the time to first analgesic request and increase the satisfaction of patients and surgeons and enhance the quality of the operative conditions. Dexmedetomidine causes more decrease in intraocular pressure than magnesium sulphate .

\section{REFERENCES}

1. Grizzard WS (1989): Ophthalmic anesthesia. Ophthalmology Annual 1989 ed. Reinecke RD, Raven press, new York :pp 265-293.

2. Kumar CM (2006): Orbital regional anesthesia: complications and their prevention. Indian J Ophthalmol ., 54(2):77-84

3. Gandhi RR, Shah AA and Patel I (2012): Use of dexmedetomidine along with bupivacaine for brachial plexus block. Natl J Med Res ., 2: 67-69.

4. Sinha R, Sharma A, Ray BR et al. (2016) :Effect of addition of magnesium to local anesthetics for peribulbar block: A prospective randomized double-blind study. Saudi Journal of Anesthesia, 10(1):64-67.

5. Bahy Eldeen HM, Fahem MR, Sameer D et al. (2011): Use of clonidine in peribulbar block in patients undergoing cataract surgery .Aust J Basic Appl Sci.,5:247-50.

6. Do SH (2013): Magnesium: a versatile drug for anesthesiologists. Korean Journal of Anesthesiology,65(1):4-8.

7. Kogler J (2009): the analgesic effect of magnesium sulfate in patients undergoing thoracotomy. Acta Clin croa ., 48(1):19-26.

8. Mostafa A (2014): Evaluation of the effect of magnesium sulphate vs clonidine as adjunct to local anesthetic using peribulabr block. Ain Shams Journal of Anesthesiology , 4: 21-26.

9. Shivakumar M, Vijaya R, Sarma J (2013): Efficacy and safety of dexmedetomidine as an additive to local anesthetics in peribulbar block for cataract surgery. Anesthesia Essays and Researches , 7(1):39-43.

10. El- Hennawy AM , Abd-Elwahab AM , Abd Elmaksoud AM et al. (2009): Addition of clonidine or dexmedetomidine to bupivacaine prolongs caudal analgesia in children .Br J anesthesia, 103:268-74.

11. Gottipathi R, Amaranath RK, Deepraj S et al. (2015): Peribulbar block: a clinical comparison between clonidine and dexmedetomidine as adjuvant with lignocaine, bupivacaine mixture. J Evidence Based Med Health , 39: 6281-6290.

12. Channabasappa SM, Shetty VR, Dharmappa SK et al. (2013) Efficacy and safety of dexmedetomidine as an additive to local anesthetics in peribulbar block for cataract surgery. Anesthesia, Essays and Researches , 7(1):39.

13. Hafez M, Fahim MR, Abdelhamid MH et al. (2016): The effect of adding dexmedetomidine to local anesthetic mixture for peribulbar block in vitreoretinal surgeries. Egyptian Journal of Anesthesia , 32(4):573579.

14. Abd El-Hamid AA (2011): Evaluation of the effect of magnesium sulphate vs. clonidine as adjunct to local anesthetic during peribulbar block. Ain Shams J Anesthesiol ., 4 (1):21-26.

15. Osama A, Ahmed M, Mahmoud G (2018):Magnesium sulphate versus dexmedetomidine as adjuvants for local anesthetics in peribulbar block for eye surgeries: clinical comparative study. The Egyptian Journal of Hospital Medicine ,72(4):4308-4312.

16. Hamawy T , Bestarous J (2013): Rocuronium versus magnesium as an adjuvant to local anesthetics in peribulbar block. Ain-Shams Journal of Anesthesiology , 6(3):317-321.

17. El Kabarity RH and Khashaba MY (2012) : Dexmedetomidine versus clonidine as an adjuvant to peribulbar block in viterretinal surgery .Ain-Shams Journal of anesthesiology ,5:288-294.

18. Tripathi A, Sharma K, Somvanshi M, Samal RL (2016): A comparative study of clonidine and dexmedetomidine as an adjunct to bupivacaine in supraclavicular brachial plexus block. Journal of Anesthesiology,32(3):344-348. 